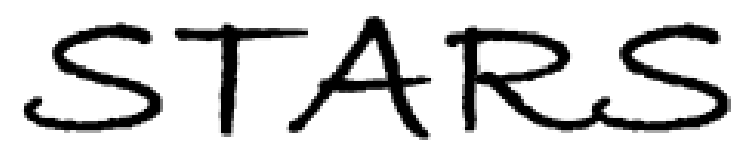

University of Central Florida

STARS

$1-1-2009$

\title{
Iron in arterial plaque: A modifiable risk factor for atherosclerosis
}

Jerome L. Sullivan

University of Central Florida

Find similar works at: https://stars.library.ucf.edu/facultybib2000

University of Central Florida Libraries http://library.ucf.edu

This Review is brought to you for free and open access by the Faculty Bibliography at STARS. It has been accepted for inclusion in Faculty Bibliography 2000s by an authorized administrator of STARS. For more information, please contact STARS@ucf.edu.

\section{Recommended Citation}

Sullivan, Jerome L., "Iron in arterial plaque: A modifiable risk factor for atherosclerosis" (2009). Faculty Bibliography 2000s. 2199.

https://stars.library.ucf.edu/facultybib2000/2199

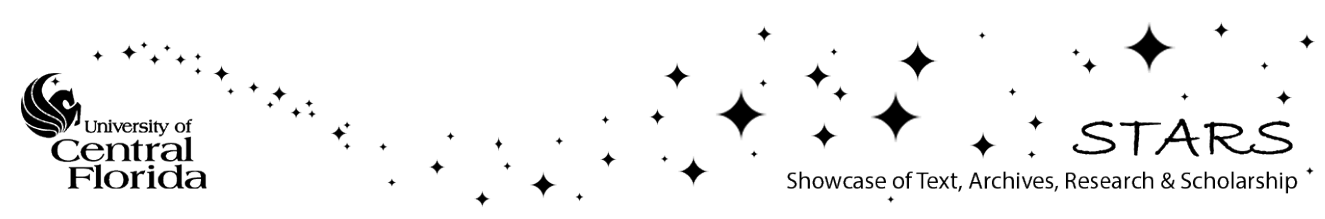


Review

\title{
Iron in arterial plaque: A modifiable risk factor for atherosclerosis
}

\author{
Jerome L. Sullivan * \\ Burnett School of Biomedical Sciences, University of Central Florida College of Medicine, Orlando, Florida, USA
}

\section{A R T I C L E I N F O}

\section{Article history:}

Received 7 April 2008

Received in revised form 3 June 2008

Accepted 13 June 2008

Available online 19 June 2008

\section{Keywords:}

Iron

Atherosclerosis

Macrophage

Ferritin

Hemochromatosis

Hepcidin

Haptoglobin

Heme oxygenase

Angiotensin

Inflammation

Interleukin-6

\begin{abstract}
A B S T R A C T
It has been proposed that iron depletion protects against cardiovascular disease. There is increasing evidence that one mechanism for this protection may involve a reduction in iron levels within atherosclerotic plaque. Large increases in iron concentration are seen in human atherosclerotic lesions in comparison to levels in healthy arterial tissue. In animal models, depletion of lesion iron levels in vivo by phlebotomy, systemic iron chelation treatment or dietary iron restriction reduces lesion size and/or increases plaque stability. A number of factors associated with increased arterial disease or increased cardiovascular events is also associated with increased plaque iron. In rats, infusion of angiotensin II increases ferritin levels and arterial thickness which are reversed by treatment with the iron chelator deferoxamine. In humans, a polymorphism for haptoglobin associated with increased cardiovascular disease is also characterized by increased lesional iron. Heme oxygenase 1 (HO1) is an important component of the system for mobilization of iron from macrophages. Human HO1 promoter polymorphisms causing weaker upregulation of the enzyme are associated with increased cardiovascular disease and increased serum ferritin. Increased cardiovascular disease associated with inflammation may be in part caused by elevated hepcidin levels that promote retention of iron within plaque macrophages. Defective retention of iron within arterial macrophages in genetic hemochromatosis may explain why there is little evidence of increased atherosclerosis in this disorder despite systemic iron overload. The reviewed findings support the concept that arterial plaque iron is a modifiable risk factor for atherogenesis.
\end{abstract}

(c) 2008 Elsevier B.V. All rights reserved.

\section{Introduction}

Nearly three decades ago, it was suggested that a state of sustained iron depletion or mild iron deficiency exert a primary protective action against ischemic heart disease [1-8]. This "iron hypothesis" was offered as an explanation of the sex difference in coronary disease incidence and the increase in incidence among women after menopause. Despite significant controversy, the idea has achieved standing as a plausible and testable hypothesis [9-13]. A protective effect of iron depletion that may have multiple beneficial consequences is decreased availability of redox-active iron in vivo [2,14].

It has been proposed that the amount of free iron available at sites of oxidative or inflammatory injury is a function of the stored iron level and that the availability of redox-active iron in vivo approaches its minimum in the state of iron depletion. There is significant experimental support for this concept [14-35]. In particular, it has been shown that removal of stored iron from the body can decrease the amount of iron deposition within atherosclerotic lesions in animal studies. Depletion of lesion iron levels in vivo by phlebotomy, systemic iron chelation treatment or dietary iron restriction reduces lesion size in these studies and increases plaque stability [18,31,36-38]. The original formulation of the iron hypothesis did not specify a

\footnotetext{
* 4475 Old Bear Run, Winter Park FL 32792, USA. Tel.: +1 4074976767.

E-mail address: jlsullivan3@gmail.com.
}

mechanism. There may well be multiple mechanisms by which iron depletion protects against heart disease. This animal work as well as a number of more recent studies focuses attention on pathogenic roles for iron within arterial plaque. Iron is present in atherosclerotic plaque at concentrations that appreciably exceed that found in healthy arterial tissue. This iron is not simply an inert component of plaque. Some of the arterial iron is redox active and the ferritin- and hemosiderin-bound iron compartment remains a reservoir of potentially reactive iron within lesions. Does this iron have a role in the production of clinical events? Does it affect plaque stability? Are there any modalities that can decrease the concentration of plaque iron? Would such removal of plaque iron by induced iron deficiency or treatment with iron chelators decrease plaque vulnerability? There have now been a number of studies that provide evidence for one potential mechanism by which iron depletion may protect against atherothrombotic disease. This article will review that work and its relevance to the iron hypothesis.

\section{Presence and modifiability of plaque iron: Early work in animal models and in human studies}

In a 1992 study, Smith et al. [39] demonstrated the presence of catalytic iron in material taken from human atherosclerotic lesions, providing important indirect support for the iron hypothesis. Iron deposits in atherosclerotic lesions in the cholesterol-fed rabbit were 
later confirmed by nuclear microscopy and in human lesions by conventional histologic staining $[38,40]$.

Matthews et al. [41] observed a large and significant decrease in total aorta cholesterol concentration after iron chelator treatment in cholesterol-fed rabbits and suggested that "perhaps [deferiprone] functions to remove free iron in the vascular subendothelium". They did not directly assess the effects of iron chelation with deferiprone on vascular iron concentration.

In a series of studies, Watt, Halliwell and colleagues [31,37,38,40,42] used nuclear microscopy to demonstrate a 7 fold increase in iron concentration within newly formed atherosclerotic lesions compared to healthy artery tissue in New Zealand White rabbits fed a $1 \%$ cholesterol diet. Iron accumulation was noted to occur at the onset of lesion formation. Repeated bleeding that decreased iron uptake in the artery wall delayed the onset of atherogenesis. In other experiments, daily treatments with the iron chelator deferoxamine for 9 weeks decreased the average lesion iron level from 95 ppm dry wt to 58 ppm dry wt $(p=0.030)$ and also significantly reduced average lesion area $(p=0.038)$. These findings provided direct evidence for a key role of iron in initiating atherogenesis.

In a seminal study, Chau and colleagues [43] differentially screened a cDNA library of human atherosclerotic aorta and discovered that genes for the iron-storage proteins, L-ferritin and $\mathrm{H}$-ferritin, are highly expressed in human atherosclerotic plaques. In situ hybridization revealed that both $\mathrm{L}$ - and $\mathrm{H}$-ferritin mRNAs were induced both in endothelial cells and macrophages of early human lesions. In advanced human lesions, the signals were also detected in the vascular smooth muscle cells (VSMC). Lesions in atherosclerotic aortas from rabbits fed a high cholesterol diet showed similar increased expression of ferritin genes. There was a close temporal association between lesion formation and increased ferritin gene expression in the rabbit aortas. Ferritin gene induction occurred early in lesion development, before the increased risk of intralesional hemorrhage seen in advanced, complex lesions.

Subsequently, these investigators found stainable iron deposits in atherosclerotic lesions in apolipoprotein E deficient (apoE-deficient) mice [18]. Stainable iron increased with age in atherosclerotic lesions as well as in heart and liver. In young mice receiving a low- iron diet for 3 months, stainable iron and iron content were much less in aortic tissues than in littermates fed standard iron replete chow. Atherosclerotic lesions were significantly smaller in the iron restricted animals and circulating autoantibodies to oxidized LDL were significantly lower. A later study by this group using the same apoEdeficient mouse model indicated that decreased arterial iron content was associated with lower expression of matrix metalloproteinase-9 (MMP-9), increased lesional collagen content and increased plaque stability [36].

The findings of Chau and colleagues on increased ferritin gene expression in VSMC of advanced human lesions [43] are consistent with the possibility that iron may be involved in the control of VSMC growth in myoproliferative intima lesions. An early study by Porreca et al. [44] directly supports this possibility. They examined the effect of the iron chelator, deferoxamine (DFO), on VSMC proliferation in a carotid balloon injury model in the rabbit. Intimal thickening and VSMC proliferation were significantly inhibited by DFO treatment.

Dabbagh et al. [45] investigated the effects of iron removal by phlebotomy or iron overload by intraperitoneal iron dextran on aortic atherosclerosis in the cholesterol-fed rabbit. They did not observe a significant effect of either intervention on lesion area. However, analysis of aortic iron content demonstrated that neither intervention succeeded in achieving a significant effect on aortic iron content in comparison with control aortas, despite producing significant differences in liver iron. The absence of an effect of this phlebotomy protocol on aortic iron likely explains the failure of these investigators to observe an effect of iron removal on lesion area.

\section{Iron in human carotid lesions}

Using electron paramagnetic resonance (EPR) spectroscopy and inductively coupled plasma mass spectroscopy (ICPMS) Davies and colleagues [46] quantified iron in ex vivo carotid lesions and in healthy human arteries. They found elevated levels of iron in the intima of lesions compared with healthy controls ( 0.370 versus $0.022 \mathrm{nmol} / \mathrm{mg}$ tissue by EPR, 0.525 versus $0.168 \mathrm{nmol} / \mathrm{mg}$ tissue by ICPMS, $P p<0.05$ in both cases). Cholesterol levels in lesions correlated positively with iron accumulation. In later work [47], iron levels in human atherosclerotic plaque correlated positively and strongly with multiple markers of protein oxidation, but not with markers of lipid oxidation.

Lapenna et al. [48] studied the relationship between serum ferritin and low molecular weight iron (LMWI) in ex vivo carotid endarterectomy specimens. They found a significant correlation of LMWI in these atherosclerotic specimens with serum ferritin. They also reported an association of plaque LMWI with markers of lipid peroxidation in the largest subgroup of patients with $<90 \%$ stenosis. In a small subgroup of patients with $>90 \%$ stenosis the association of LMWI and lipid peroxidation markers did not achieve significance. The correlation of lesional LMWI with serum ferritin is consistent with the possibility that the concentration of redox-active iron within atherosclerotic lesions can be lowered by depletion of body iron stores.

Yuan and colleagues [11,49-56] documented the presence of iron in atherosclerotic vascular tissue, suggested erythrophagocytosis as an important source of this iron, and considered the role of such iron in increasing the intralesional concentration of redox-active iron. They explored the interactions of iron and lipoproteins as plaque macrophages progress to apoptotic foam cells. In a recent study of 52 ex vivo human carotid atherosclerotic lesions [8], they found that transferrin receptor 1 (TfR1) expression was positively correlated with macrophage infiltration, ectopic lysosomal cathepsin $\mathrm{L}$ and ferritin expression. Highly expressed TfR 1 and ferritin in CD68 positive macrophages were significantly associated with development and severity of human carotid plaques, smoking and patient's symptoms. The findings suggested that pathologic macrophage iron metabolism may contribute to vulnerability of human atheroma, established risk factors and their clinical symptoms.

\section{Angiotensin II and arterial iron deposition}

Ishizaka et al. [57] found that angiotensin II infusion for 7 days in rats caused a $>20$-fold increase in ferritin protein expression over control values in aortic endothelial and adventitial cells, including monocytes/macrophages. Stainable iron was seen in the adventitial layer of aorta from angiotensin II infused animals. Iron chelation suppressed aortic induction of ferritin and heme oxygenase-1 (HO1) and suppressed upregulation of mRNA levels of monocyte chemoattractant protein-1 (MCP1). In addition, iron chelation attenuated the medial thickening and perivascular fibrosis induced by a 4 week infusion of angiotensin II. Mazzolai et al. [58] using an apoE-deficient mouse model system demonstrated that high endogenous angiotensin II is associated with the development of unstable atherosclerotic plaques. Taken together, these two studies support the concept that increased arterial iron promotes plaque instability.

\section{Haptoglobin polymorphisms and plaque iron content}

Asleh et al. [59] suggested that hemoglobin within plaque derived from microvascular hemorrhage is cleared more slowly from plaques associated with haptoglobin (Hp) 2-2 genotype as compared to Hp 11 plaques. The Hp 2-2 genotype is associated with an increased risk of atherosclerotic cardiovascular disease. These investigators then created a type $2 \mathrm{Hp}$ allele in the apoE-deficient mouse and explored the effect of Hp 2-2 genotype on iron, lipid peroxidation and macrophage accumulation in plaque. They found that "intra-plaque 
hemorrhage generates greater iron deposition in mice with the $\mathrm{Hp} 2-2$ genotype, leading to increased oxidation of lipids and other cellular constituents of the plaque." Slower clearance of hemoglobin-derived iron within lesions, in this case because of an Hp polymorphism, causes increased lipid peroxidation and macrophage accumulation in atherosclerotic lesions. In a later study [60], they found impaired clearance of free hemoglobin and iron from atherosclerotic plaques in Hp 2-2 diabetic patients. They concluded that Hp genotype is a major determinant of the iron concentration of atheroscerotic plaque iron derived from intralesional hemorrhage.

\section{Heme oxygenase-1 polymorphisms and plaque iron}

A similar pattern may occur with promoter polymorphisms in HO1, an inducible enzyme that catalyzes the rate limiting step in heme catabolism. Heme catabolism is a key function in mobilizing macrophage iron derived from ingested erythrocytes. Alterations in the activity of $\mathrm{HO} 1$ influence the rate of clearance of hemoglobin-derived iron from macrophages. In the HO1 deficient mouse (HO1-/-) conspicuous iron loading is seen in Kupffer cells, hepatocytes, hepatic vascular tissue, and renal cortical tubules [61]. In another study involving HO1-/ - mice, increased levels of reactive oxygen species production in macrophages and increased atherosclerotic plaque were thought to be a result of relatively decreased intracellular levels of biliverdin or bilirubin, or increased intracellular levels of iron stores [62]. Pharmacologic inhibition of HO1 is associated with marked elevation in serum ferritin without significant changes in several other acute phase reactants [63].

In diabetic humans, HO1 promoter polymorphisms causing weaker upregulation of the enzyme are associated with both increased cardiovascular disease [64] and with significantly increased serum ferritin [65]. Taken together, these findings are consistent with the concept that slower clearance of hemoglobin-derived iron may promote atherosclerotic plaque progression.

Statins have been reported to induce HO1 in murine macrophages [66] and in human endothelial cells [67] raising the possibility that this may be a basis for the protective actions of statins independently of their cholesterol lowering effect. It has been proposed that statins may stabilize atherosclerotic plaques in part by inducing intralesional $\mathrm{HO}$, facilitating iron mobilization, and thereby lowering plaque iron levels [7].

\section{Quantitation of carotid plaque iron by MRI based T2* measurement}

Raman et al. [68] investigated the role of iron deposition in carotid plaque instability using a novel approach of in vivo plaque characterization by a noninvasive, noncontrast magnetic resonance based $\mathrm{T} 2 *$ measurement. The method was validated using ex vivo plaque analyses of intra-plaque iron composition. Symptomatic patients had significantly shorter plaque $\mathrm{T}^{*}$ values $(20.0 \pm 1.8 \mathrm{~ms})$ compared with asymptomatic patients $(34.4 \pm 2.7 \mathrm{~ms}, p<0.001)$, respectively, which is consistent with a shift in iron from low molecular weight $\mathrm{Fe}(\mathrm{III})$ to greater amounts of T2*-shortening forms of iron. Such T2* shortening forms were thought to be iron aggregates represented by hemosiderin and ferritin. Symptom-producing plaques demonstrated characteristic changes in iron forms by ex vivo analysis. The findings support the dynamic presence of iron in the microenvironment of atherosclerotic plaque. Additional studies are needed to better characterize the significance of the various forms of iron within plaque and to assess the clinical utility of noninvasive measures of plaque iron in the clinical determination of plaque stability.

\section{Inflammation, IL-6, hepcidin and iron in arterial plaque}

Hepcidin level is a major determinant of the amount of iron retained within macrophages [69-72]. Production of hepcidin is regulated by a number of interrelated factors. Elevated levels, which favor macrophage iron retention, are encountered with increased iron intake, infection and inflammation. Reduced hepcidin levels are associated with iron deficiency, hypoxia, anemia and homozygous hemochromatosis. Interleukin 6 (IL-6) upregulation as seen in inflammatory states induces hepcidin synthesis [69].

Hepcidin production is regulated over a large concentration range. In one recent study [73], urine concentrations of hepcidin were reduced by approximately 7 fold in iron deficiency and 13 fold in hereditary hemochromatosis. At the other end of the spectrum, there was a 27 fold increase in urinary hepcidin in an endotoxemia model in which healthy volunteers received E. coli lipopolysaccharide in the amount of $2 \mathrm{ng} / \mathrm{kg}$ body weight i.v. Iron deficiency and hemochromatosis are associated with dramatically different amounts of storage iron, however, both conditions are characterized by similarly very low levels of hepcidin. Inflammation, in part secondary to upregulation of IL-6, can be associated with very high concentrations of hepcidin with consequently high levels of iron retention within macrophages. This situation typically occurs, for example, in anemia of inflammation (i.e. "anemia of chronic disorders"). The condition is sometimes described as "functional iron deficiency" a term intended to indicate a decreased availability of iron for erythropoiesis, despite a state of macrophage iron overload. The reported association of inflammation and atherogenesis may be in part related to impaired clearance of iron from plaque macrophages resulting from high inflammation-induced levels of hepcidin [7].

\section{Genetic hemochromatosis and defective iron retention in the macrophage}

Genetic hemochromatosis is another factor that could strongly influence the iron concentration of arterial plaque. Because HFE mutations are almost always associated with very low hepcidin concentrations and consequently with decreased retention of iron by the macrophage [71,72], it appears likely that these mutations may, counter-intuitively, cause more rapid clearance of iron from arterial lesions. The classic finding in inherited hemochromatosis is misplaced hepatic iron. The disease is associated with iron loading of hepatocytes and a relative lack of iron in the normal reticuloendothelial sites, i.e. within Kupffer cells. Hepcidin has emerged as a major regulator of iron distribution in the body. Decreased levels of hepcidin, especially the very low levels associated with both iron deficiency anemia and with genetic hemochromatosis, have the dual effect of enhancing iron absorption from gut and simultaneously allowing release of iron from storage sites, e.g. from macrophages.

The rate of iron release from arterial plaque macrophages in those with HFE mutations has not been specifically examined, to my knowledge. It is well known that the very low levels of hepcidin observed in iron deficiency mediate the release of iron from essentially all storage sites for iron mobilization to support erythropoiesis in the marrow. There is no reason to believe that iron in intralesional macrophages is exempt from this mobilization process. Indeed, animal studies showing decreased plaque area in association with experimental arterial iron reduction $[18,31,37]$ strongly support the possibility that such arterial iron is just as mobilizable as it is from other iron-storage locations in the body.

The large increase in body iron that can be seen especially in the homozygous form of the disease may enhance susceptibility to reperfusion injury and may also diffusely cause arterial intimal thickening, while at the same time affording some specific protection from iron induced plaque vulnerability. Many unanswered questions remain on the impact of HFE mutations on arterial iron levels, plaque stability, intimal proliferation and endothelial function. The apparent lack of increased risk for arterial structural lesions in genetic hemochromatosis [74] has often been cited as evidence against the iron hypothesis $[7,75]$. However, the effects of extremely low hepcidin 
levels on lowering atherosclerotic plaque iron may explain how iron can have an important role in atherogenesis yet paradoxically not cause an increased prevalence of atherosclerosis in inherited iron overload [7].

\section{The FeAST trial}

Findings of a first randomized trial of mild iron reduction therapy in elderly patients with established peripheral vascular disease (the "FeAST" trial) have been recently reported $[9,76,77]$. The trial assessed the potential benefit of mild iron reduction therapy in secondary prevention of cardiovascular disease. It was therefore not a fully valid test of primary prevention as postulated by the iron hypothesis. No overall statistically significant cardiovascular benefit was found. However, in the youngest quartile at entry there were highly significant reductions in all cause mortality and in combined death plus non-fatal myocardial infarction and stroke in association with iron reduction therapy. Age was a prespecified stratification variable for randomization. In all age quartiles, iron reduction therapy was associated with a highly significant reduction in cancer mortality vs control patients.

The FeAST trial may have failed to observe a cardiovascular benefit from iron reduction in older subjects because the study design intentionally disallowed achievement of full iron depletion. Participants in FeAST who were randomized to undergo iron reduction experienced a decrease in mean serum ferritin from $122.5 \mathrm{ng} / \mathrm{mL}$ to $79.7 \mathrm{ng} / \mathrm{mL}$. Those with iron reduction ended the observation period with stored iron levels substantially higher than those observed in menstruating women who typically have serum ferritin values below $30 \mathrm{ng} / \mathrm{mL}$.

In the FeAST trial, there was also no attempt to directly measure arterial iron concentration or the effects of the iron reduction intervention on this parameter. Therefore the trial results do not directly address the role of plaque iron in atherogenesis. However, it provides important information for a future trial of induced iron depletion or iron deficiency on plaque iron and clinical events. It provides important reassurance of the safety of iron reduction therapy even in patients with established atherosclerotic disease. The improved survival of the youngest quartile at entry suggests that iron reduction with lower iron-storage targets and beginning at an earlier age might prove more beneficial. It is also reassuring that even this modest level of iron reduction was significantly associated with lower cancer mortality in subjects of all ages. There was a $36.7 \%$ lower risk of cancer occurrence $(p=0.023)$ and a $68.6 \%$ lower cancer mortality $(p=0.003)$ compared to control patients $[78,79]$.

\section{Iron in arterial plaque: A modifiable risk factor for atherosclerosis}

These findings from animal models of atherosclerosis and from studies of human atherosclerotic plaque provide support for the concept that elevated arterial iron levels play a significant role in the pathogenesis of atherosclerosis. Both the animal studies and long clinical experience with the effects of iron deficiency anemia on storage iron show that iron in arterial plaque can be mobilized for erythropoiesis and thereby reduced in concentration. It should be feasible to achieve the normally low iron concentration of healthy arterial tissue and hold it at low levels indefinitely by induction and maintenance of reduced total body iron. The degree and duration of iron reduction required in humans to completely normalize atherosclerotic plaque iron concentrations to that of healthy arterial tissue is a key question that must be addressed in future studies. The demonstration that carotid plaque iron can be quantified by a noninvasive, noncontrast magnetic resonance based $\mathrm{T}^{*}$ measurement [68] suggests one method by which plaque iron can be monitored in future studies to address this key question. In addition, how much iron reduction therapy would be required for primary prevention of plaque formation and possibly for decreasing the size and/or vulnerability of existing atherosclerotic plaque will require future human studies. It is possible that significant benefit might be achieved by induction of iron depletion, defined as the absence of storage iron without anemia. Or, induction of mild iron deficiency anemia may be required for maximal benefit.

\section{Concluding comment: Is stored iron safe?}

Suggesting that one disorder, i.e. atherosclerotic plaque, might be treatable by the induction of a second disorder, i.e. iron depletion, may be seen as a controversial proposal largely because there is a deeply held and widely prevalent assumption that iron in storage is inherently safe. The assumption is based ultimately on decades old traditional medical practices rather than on appropriately designed rigorous clinical trials. It has been previously noted [14] that "A benefit of iron depletion can only be rigorously demonstrated in relation to the state of iron in excess of needs (ie, the condition of having iron in storage). It has not been widely appreciated that the safety of stored iron can only be shown with clarity in studies of the same design. Absence of proof that iron depletion is beneficial implies an absence of proof of the safety of stored iron. Because of the deeply rooted assumption that stored iron is safe, appropriate trials to rule out the potential hazards of iron stores have not been undertaken."

Among affluent populations, in the presence of plentiful dietary iron and in the absence of prevalent parasites that cause occult bleeding, iron is stored in the body in excess of needs. Under these conditions, unless there is some other source of chronic iron loss, iron availability is generally not a factor that limits growth rate or achievement of maximal hemoglobin levels. However, this does not prove that acquisition of stored iron is optimal for long term survival. The analogy of caloric restriction is instructive. Among affluent populations, the availability of an abundant supply of high calorie foods is associated with maximal growth rates and prevalent obesity. A gross excess of calories may be optimal for growth rate and maximal achieved adult weight and height, but not for long term survival. The optimal caloric intake for longevity in animal experiments is substantially smaller than ad libitum intakes in the presence of caloric excess. Regulatory processes may have evolved that tend to assure retention of an excess of calories in the form of fat deposition against the possibility of future famine. A similar pattern may have evolved with respect to iron retention. The accumulation of an excess of iron beyond needs may have favored survival during human evolution under conditions of limited iron availability. Under affluent conditions, these processes may guarantee that iron in excess of the optimum for longevity is retained. As with caloric intake, there may be two optima for iron intake: a high level to achieve maximal growth and hemoglobin level, and a significantly lower level to achieve maximal longevity. Experimental strategies to establish the fundamental safety of storage iron should include studies on the effects of iron restriction on longevity [14].

Roles for iron have been proposed in a broad range of serious disorders including vascular disease [1], cancer [79-82], diabetes $[19,83,84]$, infectious diseases [85], neurodegenerative diseases [86$88]$ and the process of senescence [6,89-91]. There is a critical need to rethink the assumption (an assumption based on traditional medical practices rather than rigorous testing) that stored iron is safe until proved otherwise. Future studies on the role of iron in atherogenesis and plaque vulnerability should not be compromised by perceived ethical constraints based solely on this unproven assumption. Due consideration must be given to the risk of failing to detect a significant benefit because of inadequate iron reduction protocols in future trials.

\section{References}

[1] J.L. Sullivan, Iron and the sex difference in heart disease risk, Lancet 1 (1981) 1293-1294. 
[2] J.L. Sullivan, The iron paradigm of ischemic heart disease, Am. Heart J. 117 (1989) 1177-1188.

[3] J.L. Sullivan, Stored iron and ischemic heart disease. Empirical support for a new paradigm, Circulation 86 (1992) 1036-1037.

[4] J.L. Sullivan, Stored iron and myocardial perfusion deficits, Am. Heart J. 143 (2002) 193-195.

[5] J.L. Sullivan, Are menstruating women protected from heart disease because of, or in spite of, estrogen? Relevance to the iron hypothesis, Am. Heart J. 145 (2003) 190-194.

[6] J.L. Sullivan, Stored iron and vascular reactivity, Arterioscler Thromb. Vasc. Biol. 25 (2005) 1532-1535.

[7] J. Sullivan, Macrophage iron, hepcidin, and atherosclerotic plaque stability, Exp. Biol. Med. 232 (2007) 1014-1020.

[8] W. Li, L.H. Xu, C. Forssel, J.L. Sullivan, X.M. Yuan, Over-expression of transferrin receptor and ferritin related to clinical symptoms and destabilization of human carotid plaques, Exp. Biol. Med. (2008) 0711-07RM.

[9] F.B. Hu, The iron-heart hypothesis: search for the ironclad evidence, JAMA 297 (2007) 639-641

[10] J.J.M. Marx, A.E.R. Kartikasari, N.A. Georgiou, Can iron chelators influence the progression of atherosclerosis? Hemoglobin 32 (2008) 123-134.

[11] X.M. Yuan, W. Li, The iron hypothesis of atherosclerosis and its clinical impact, Ann. Med. 35 (2003) 578-591.

[12] M. Franchini, G. Targher, M. Montagnana, G. Lippi, Iron and thrombosis, Ann. Hematol. 87 (2008) 167-173.

[13] H. Zheng, R. Cable, B. Spencer, N. Votto, S.D. Katz, Iron stores and vascular function in voluntary blood donors, Arterioscler. Thromb. Vasc. Biol. 25 (2005) 1577-1583.

[14] J. Sullivan, Is stored iron safe? J. Lab. Clin. Med. 144 (2004) 280-284.

[15] J.L. Sullivan, G.O. Till, P.A. Ward, Iron depletion decreases lung injury after systemic complement activation. Fed. Proc. 45 (1986) 452

[16] J.L. Sullivan, G.O. Till, P.A. Ward, R.B. Newton, Nutritional iron restriction diminishes acute complement-dependent lung injury, Nutr. Res. 9 (1989) 625-634.

[17] M. Barollo, R. D'Inca, M. Scarpa, V. Medici, R. Cardin, W. Fries, I. Angriman, G.C. Sturniolo, Effects of iron deprivation or chelation on DNA damage in experimental colitis, Int. J. Colorectal. Dis. 19 (2004) 461-466.

[18] T.S. Lee, M.S. Shiao, C.C. Pan, L.Y. Chau, Iron-deficient diet reduces atherosclerotic lesions in apoE-deficient mice, Circulation 99 (1999) 1222-1229.

[19] F.S. Facchini, K.L. Saylor, Effect of iron depletion on cardiovascular risk factors: studies in carbohydrate-intolerant patients, Ann. N. Y. Acad. Sci. 967 (2002) 342-351.

[20] F.S. Facchini, K.L. Saylor, A low-iron-available, polyphenol-enriched, carbohydraterestricted diet to slow progression of diabetic nephropathy, Diabetes 52 (2003) 1204-1209.

[21] F.S. Facchini, Near-iron deficiency-induced remission of gouty arthritis, Rheumatology (Oxford) 42 (2003) 1-6.

[22] A.J. Ghio, T.P. Kennedy, K.M. Crissman, J.H. Richards, G.E. Hatch, Depletion of iron and ascorbate in rodents diminishes lung injury after silica, Exp. Lung. Res. 24 (1998) 219-232.

[23] S.M. Grant, J.A. Wiesinger, J.L. Beard, M.T. Cantorna, Iron-deficient mice fail to develop autoimmune encephalomyelitis, J. Nutr. 133 (2003) 2635-2638.

[24] H. Hayashi, T. Takikawa, N. Nishimura, M. Yano, Serum aminotransferase levels as an indicator of the effectiveness of venesection for chronic hepatitis C, J. Hepatol. 22 (1995) 268-271.

[25] J. Kato, K. Miyanishi, M. Kobune, T. Nakamura, K. Takada, R. Takimoto, Y. Kawano, S. Takahashi, M. Takahashi, Y. Sato, T. Takayama, Y. Niitsu, Long-term phlebotomy with low-iron diet therapy lowers risk of development of hepatocellular carcinoma from chronic hepatitis C, J. Gastroenterol. 42 (2007) 830-836.

[26] H.T. Lee, L.L. Chiu, T.S. Lee, H.L. Tsai, L.Y. Chau, Dietary iron restriction increases plaque stability in apolipoprotein-e-deficient mice, J. Biomed. Sci. 10 (2003) 510-517.

[27] C.W. Levenson, R.G. Cutler, B. Ladenheim, J.L. Cadet, J. Hare, M.P. Mattson, Role of dietary iron restriction in a mouse model of Parkinson's disease, Exp. Neurol. 190 (2004) 506-514

[28] K. Otogawa, T. Ogawa, R. Shiga, K. Nakatani, K. Ikeda, Y. Nakajima, N. Kawada, Attenuation of acute and chronic liver injury in rats by iron-deficient diet, Am. J. Physiol. Regul. Integr. Comp. Physiol. 294 (2008) R311-R320.

[29] Y.Y. Park, B.M. Hybertson, R.M. Wright, J.E. Repine, Serum ferritin increases in hemorrhaged rats that develop acute lung injury: effect of an iron-deficient diet, Inflammation 27 (2003) 257-263.

[30] A. Patt, I.R. Horesh, E.M. Berger, A.H. Harken, J.E. Repine, Iron depletion or chelation reduces ischemia/reperfusion-induced edema in gerbil brains, J. Pediatr. Surg. 25 (1990) 224-227.

[31] D. Ponraj, J. Makjanic, P.S. Thong, B.K. Tan, F. Watt, The onset of atherosclerotic lesion formation in hypercholesterolemic rabbits is delayed by iron depletion, FEBS Lett. 459 (1999) 218-222.

[32] K. Sasaki, K. Hashida, Y. Michigami, S. Bannai, N. Makino, Restored vulnerability of cultured endothelial cells to high glucose by iron replenishment, Biochem. Biophys. Res. Commun. 289 (2001) 664-669.

[33] S. Shoham, M.B.H. Youdim, Nutritional iron deprivation attenuates kainateinduced neurotoxicity in rats: implications for involvement of iron in neurodegeneration, Ann. N.Y. Acad. Sci. 1012 (2004) 94-114.

[34] H. van Jaarsveld, G.F. Pool, Beneficial effects of blood donation on high density lipoprotein concentration and the oxidative potential of low density lipoprotein, Atherosclerosis 161 (2002) 395-402.

[35] D.S. Webber, I. Lopez, R.A. Korsak, S. Hirota, D. Acuna, J. Edmond, Limiting iron availability confers neuroprotection from chronic mild carbon monoxide exposure in the developing auditory system of the rat, J. Neurosci. Res. 80 (2005) 620-653

[36] H.T. Lee, L.L. Chiu, T.S. Lee, H.L. Tsai, L.Y. Chau, Dietary iron restriction increases plaque stability in apolipoprotein-e-deficient mice, J. Biomed. Sci. 10 (2003) 510-517.

[37] R. Minqin, R. Rajendran, N. Pan, T.B. Kwong-Huat, W.Y. Ong, F. Watt, B. Halliwell The iron chelator desferrioxamine inhibits atherosclerotic lesion development and decreases lesion iron concentrations in the cholesterol-fed rabbit, Free Radic. Biol. Med. 38 (2005) 1206-1211.

[38] F. Watt, R. Rajendran, M.Q. Ren, B.K.H. Tan, B. Halliwell, A nuclear microscopy study of trace elements $\mathrm{Ca}, \mathrm{Fe}, \mathrm{Zn}$ and $\mathrm{Cu}$ in atherosclerosis, Nucl. instrum. methods phys. res., B Beam interact. mater. atoms 249 (2006) 646-652.

[39] C. Smith, M.J. Mitchinson, O.I. Aruoma, B. Halliwell, Stimulation of lipid peroxidation and hydroxyl-radical generation by the contents of human atherosclerotic lesions, Biochem. J. 286 (Pt 3) (1992) 901-905.

[40] P.S. Thong, M. Selley, F. Watt, Elemental changes in atherosclerotic lesions using nuclear microscopy, Cell Mol. Biol. (Noisy. -Le-Grand) 42 (1996) 103-110.

[41] A.J. Matthews, G.M. Vercellotti, H.J. Menchaca, P.H. Bloch, V.N. Michalek, P.H Marker, J. Murar, H. Buchwald, Iron and atherosclerosis: inhibition by the iron chelator deferiprone (L1), J. Surg. Res. 73 (1997) 35-40.

[42] R. Minqin, F. Watt, B.T. Huat, B. Halliwell, Correlation of iron and zinc levels with lesion depth in newly formed atherosclerotic lesions, Free. Radic. Biol. Med. 34 (2003) 746-752.

[43] J.H. Pang, M.J. Jiang, Y.L. Chen, F.W. Wang, D.L. Wang, S.H. Chu, L.Y. Chau, Increased ferritin gene expression in atherosclerotic lesions, J. Clin. Invest 97 (1996) 2204-2212.

[44] E. Porreca, S. Ucchino, C. Di Febbo, N. Di Bartolomeo, D. Angelucci, A.M Napolitano, A. Mezzetti, F. Cuccurullo, Antiproliferative effect of desferrioxamine on vascular smooth muscle cells in vitro and in vivo, Arterioscler. Thromb. 14 (1994) 299-304.

[45] A.J. Dabbagh, G.T. Shwaery, J.F. Keaney Jr., B. Frei, Effect of iron overload and iron deficiency on atherosclerosis in the hypercholesterolemic rabbit, Arterioscler Thromb. Vasc. Biol. 17 (1997) 2638-2645

[46] N. Stadler, R.A. Lindner, M.J. Davies, Direct detection and quantification of transition metal ions in human atherosclerotic plaques: evidence for the presence of elevated levels of iron and copper, Arterioscler. Thromb. Vasc. Biol. 24 (2004) 949-954.

[47] N. Stanley, N. Stadler, A.A. Woods, P.G. Bannon, M.J. Davies, Concentrations of iron correlate with the extent of protein, but not lipid, oxidation in advanced human atherosclerotic lesions, Free Radic. Biol. Med. 40 (2006) 1636-1643.

[48] D. Lapenna, S.D. Pierdomenico, G. Ciofani, S. Ucchino, M. Neri, M.A. Giamberardino, F. Cuccurullo, Association of body iron stores with low molecular weight iron and oxidant damage of human atherosclerotic plaques, Free Radic. Biol. Med 42 (2007) 492-498.

[49] X.M. Yuan, U.T. Brunk, A.G. Olsson, Effects of iron- and hemoglobin-loaded human monocyte-derived macrophages on oxidation and uptake of LDL, Arterioscler. Thromb. Vasc. Biol. 15 (1995) 1345-1351.

[50] X.M. Yuan, W.L. Anders, A.G. Olsson, U.T. Brunk, Iron in human atheroma and LDL oxidation by macrophages following erythrophagocytosis, Atherosclerosis 124 (1996) 61-73.

[51] X.M. Yuan, U.T. Brunk, Iron and LDL-oxidation in atherogenesis, APMIS 106 (1998) $825-842$.

[52] X.M. Yuan, Apoptotic macrophage-derived foam cells of human atheromas are rich in iron and ferritin, suggesting iron-catalysed reactions to be involved in apoptosis, Free. Radic. Res. 30 (1999) 221-231.

[53] X.M. Yuan, W. Li, S.K. Baird, M. Carlsson, O. Melefors, Secretion of ferritin by ironladen macrophages and influence of lipoproteins, Free. Radic. Res. 38 (2004) 1133-1142.

[54] W. Li, L.H. Xu, X.M. Yuan, Macrophage hemoglobin scavenger receptor and ferritin accumulation in human atherosclerotic lesions, Ann. N. Y. Acad. Sci 1030 (2004) 196-201.

[55] W. Li, A. Hellsten, L.H. Xu, D.M. Zhuang, K. Jansson, U.T. Brunk, X.M. Yuan, Foam cell death induced by 7[beta]-hydroxycholesterol is mediated by labile iron-driven oxidative injury: Mechanisms underlying induction of ferritin in human atheroma, Free Radic. Biol. Med. 39 (2005) 864-875.

[56] W. Li, M. Ostblom, L.H. Xu, A. Hellsten, P. Leanderson, B. Liedberg, U.T. Brunk, J.W Eaton, X.M. Yuan, Cytocidal effects of atheromatous plaque components: the death zone revisited, FASEB J. 20 (2006) 2281-2290.

[57] N. Ishizaka, K. Saito, I. Mori, G. Matsuzaki, M. Ohno, R. Nagai, Iron chelation suppresses ferritin upregulation and attenuates vascular dysfunction in the aorta of angiotensin Il-infused rats, Arterioscler. Thromb. Vasc. Biol. 25 (2005) 2282-2288.

[58] L. Mazzolai, M.A. Duchosal, M. Korber, K. Bouzourene, J.F. Aubert, H. Hao, V. Vallet, H. Brunner, J. Nussberger, G. Gabbiani, D. Hayoz, Endogenous angiotensin Il induces atherosclerotic plaque vulnerability and elicits a Th1 response in ApoE-/ - mice, Hypertension 44 (2004) 277-282.

[59] R. Asleh, J. Guetta, S. Kalet-Litman, R. Miller-Lotan, A.P. Levy, Haptoglobin genotype- and diabetes-dependent differences in iron-mediated oxidative stress in vitro and in vivo, Circ. Res. 96 (2005) 435-441.

[60] Moreno, P. R., Purushothaman, K. R., Purushothaman, Meerarani, Munter, P., Levy, N. S., Winterstern, A, Levy, A. P. Haptoglobin genotype is a major determinant of the amount of iron in the human atherosclerotic plaque. [Submitted] 2008.

[61] K.D. Poss, S. Tonegawa, Heme oxygenase 1 is required for mammalian iron reutilization, PNAS 94 (1997) 10919-10924.

[62] L.D. Orozco, M.H. Kapturczak, B. Barajas, X. Wang, M.M. Weinstein, J. Wong, J. Deshane, S. Bolisetty, Z. Shaposhnik, D.M. Shih, A. Agarwal, A.J. Lusis, J.A. Araujo, 
Heme oxygenase- 1 expression in macrophages plays a beneficial role in atherosclerosis, Circ. Res. 100 (2007) 1703-1711.

[63] L. Berglund, R.A. Galbraith, L. Emtestam, G.S. Drummond, B. Angelin, A. Kappas, Heme oxygenase inhibitors transiently increase serum ferritin concentrations without altering other acute-phase reactants in man, Pharmacology 59 (1999) 51-56.

[64] Y.H. Chen, S.J. Lin, M.W. Lin, H.L. Tsai, S.S. Kuo, J.W. Chen, M.J. Charng, T.C. Wu, L.C. Chen, Y.A. Ding, W.H. Pan, Y.S. Jou, L.Y. Chau, Microsatellite polymorphism in promoter of heme oxygenase- 1 gene is associated with susceptibility to coronary artery disease in type 2 diabetic patients, Hum. Genet 111 (2002) 1-8.

[65] Y.H. Chen, L.Y. Chau, J.W. Chen, S.J. Lin, Serum bilirubin and ferritin levels link between heme oxygenase- 1 gene promoter polymorphism and susceptibility to coronary artery disease in diabetic patients, Diabetes Care (2008) dc07-d2126.

[66] J.C. Chen, K.C. Huang, W.W. Lin, HMG-CoA reductase inhibitors upregulate heme oxygenase-1 expression in murine RAW264.7 macrophages via ERK, p38 MAPK and protein kinase G pathways, Cell. Signal. 18 (2006) 32-39.

[67] F. Ali, S.S. Hamdulay, A.R. Kinderlerer, J.J. Boyle, E.A. Lidington, T. Yamaguchi, M.P. Soares, D.O. Haskard, A.M. Ralndi, J.C. Mason, Statin-mediated cytoprotection of human vascular endothelial cells: a role for Kruppel-like factor 2-dependent induction of heme oxygenase-1, J. Thromb. Haemostasis 5 (2007) 2537-2546.

[68] S.V. Raman, M.W. Winner III, T. Tran, M. Velayutham, O.P. Simonetti, P.B. Baker, J. Olesik, B. McCarthy, A.K. Ferketich, J.L. Zweier, In vivo atherosclerotic plaque characterization using magnetic susceptibility distinguishes symptom-producing plaques, J. Am. Coll. Cardiol. Img. 1 (2008) 49-57.

[69] E. Nemeth, S. Rivera, V. Gabayan, C. Keller, S. Taudorf, B.K. Pedersen, T. Ganz, IL-6 mediates hypoferremia of inflammation by inducing the synthesis of the iron regulatory hormone hepcidin, J. Clin. Invest. 113 (2004) 1271-1276.

[70] E. Kemna, P. Pickkers, E. Nemeth, H. van der Hoeven, D. Swinkels, Time-course analysis of hepcidin, serum iron, and plasma cytokine levels in humans injected with LPS, Blood 106 (2005) 1864-1866.

[71] E. Nemeth, T. Ganz, Regulation of iron metabolism by hepcidin, Annual. Review. of. Nutrition. 26 (2006) 323-342.

[72] T. Ganz, E. Nemeth, Iron imports. IV. Hepcidin and regulation of body iron metabolism, Am. J. Physiol. Gastrointest. Liver. Physiol. 290 (2006) G199-G203.

[73] E. Kemna, H. Tjalsma, C. Laarakkers, E. Nemeth, H. Willems, D. Swinkels, Novel urine hepcidin assay by mass spectrometry, Blood 106 (2005) 3268-3270.

[74] R.F. Franco, M.A. Zago, M.D. Trip, H. ten Cate, E.A. van den, M.H. Prins, J.J. Kastelein, P.H. Reitsma, Prevalence of hereditary haemochromatosis in premature atherosclerotic vascular disease, Br. J. Haematol. 102 (1998) 1172-1175.

[75] J.L. Sullivan, L.R. Zacharski, Hereditary haemochromatosis and the hypothesis that iron depletion protects against ischemic heart disease, Eur. J Clin. Invest 31 (2001) 375-377.

[76] L.R. Zacharski, B.K. Chow, P.S. Howes, G. Shamayeva, J.A. Baron, R.L. Dalman, D.J. Malenka, C.K. Ozaki, P.W. Lavori, Reduction of iron stores and cardiovascular outcomes in patients with peripheral arterial disease: a randomized controlled trial, JAMA 297 (2007) 603-610.

[77] J.L. Sullivan, S.D. Katz, Iron reduction and cardiovascular outcomes, JAMA 297 (2007) 2075.

[78] Zacharski, L. R., Chow, B., Howes, P. S., Lavori, P. W., Shamayeva, G., Baron, John A., Dalman, R., Malenka, D., Ozaki, K. Effect of Reduction of Iron (Fe) Stores on Cardiovascular and Cancer Outcomes in Patients with Advanced Peripheral Arterial Disease (PAD): VA Cooperative Study \#410, the Iron (Fe) and Atherosclerosis Study (FeAST). Abstract \#1807. Blood 108[11], 512a-513a. 11-16-2006.

[79] L.R. Zacharski, B.K. Chow, P.S. Howes, G. Shamayeva, A. Baron, R. John, R. Dalman, D. Malenka, C. Ozaki, Keith, P.W. Lavori, Decreased Cancer Risk Following Reduction of Iron Stores in Patients with Peripheral Arterial Disease. Results from a randomized trial, J. Natl. Cancer Inst. (2008) djn209.

[80] R.G. Stevens, B.I. Graubard, M.S. Micozzi, K. Neriishi, B.S. Blumberg, Moderate elevation of body iron level and increased risk of cancer occurrence and death, Int. J. Cancer. 56 (1994) 364-369.

[81] S. Toyokuni, Iron and carcinogenesis: from Fenton reaction to target genes, Redox. Rep. 7 (2002) 189-197.

[82] Y. Yu, Z. Kovacevic, D.R. Richardson, Tuning cell cycle regulation with an iron key, Cell Cycle 6 (2007) 1982-1994.

[83] N.W. Hua, R.A. Stoohs, F.S. Facchini, Low iron status and enhanced insulin sensitivity in lacto-ovo vegetarians, Br. J. Nutr. 86 (2001) 515-519.

[84] S. Swaminathan, V.A. Fonseca, M.G. Alam, S.V. Shah, The role of iron in diabetes and its complications, Diabetes Care (2007) dc06-d2625.

[85] E.D. Weinberg, Iron and infection, Microbiol. Rev. 42 (1978) 45-66.

[86] D.R. Richardson, Novel chelators for central nervous system disorders that involve alterations in the metabolism of iron and other metal ions, Ann. N.Y. Acad. Sci. 1012 (2004) 326-341.

[87] KJ.H. Robson, D.J. Lehmann, V.L.C. Wimhurst, KJ. Livesey, M. Combrinck, A.T. Merryweather-Clarke, D.R. Warden, A.D. Smith, Synergy between the C2 allele of transferrin and the C282Y allele of the haemochromatosis gene (HFE) as risk factors for developing Alzheimer's disease, J. Med. Genet. 41 (2004) 261-265.

[88] L. Zecca, M.B.H. Youdim, P. Riederer, J.R. Connor, R.R. Crichton, Iron, brain ageing and neurodegenerative disorders, Nat. Rev. Neurosci. 5 (2004) 863-873.

[89] A.S. Polla, L.L. Polla, B.S. Polla, Iron as the malignant spirit in successful ageing, Ageing Res Rev. 2 (2003) 25-37.

[90] H.R. Massie, V.R. Aiello, T.R. Williams, Inhibition of iron absorption prolongs the life span of Drosophila, Mech. Ageing Dev. 67 (1993) 227-237.

[91] J. Xu, M. Knutson, C. Carter, C. Leeuwenburgh, Calorie restriction attenuates agerelated iron accumulation and oxidative stress in skeletal muscle and improves indices of sarcopenia. [Submitted] 2008. 